\title{
Mendelian susceptibility to mycobacterial diseases due to complete ISG15 deficiency
}

INSERM

\section{Source}

INSERM. (1999). Orphanet: an online rare disease and orphan drug data base. Mendelian susceptibility to mycobacterial diseases due to complete ISG15 deficiency.

ORPHA:319563

Mendelian susceptibility to mycobacterial diseases (MSMD) due to complete ISG15

deficiency is a genetic variant of MSMD (see this term) characterized by Bacille CalmetteGuérin (BCG) infections. 